\title{
Kinetic model of water vapour adsorption by gluten-free starch
}

\author{
Aneta Ocieczek ${ }^{1 *}$, Robert Kostek ${ }^{2}$, and Millena Ruszkowska \\ ${ }^{1}$ Department of Hotel and Tourism Management, Gdynia Maritime University, Morska 83, 81-225 Gdynia, Poland \\ ${ }^{2}$ University of Technology and Life Sciences in Bydgoszcz, Al. Prof. S. Kaliskiego 7, 85-796 Bydgoszcz, Poland \\ Received December 17, 2013; accepted November 20, 2014
}

\begin{abstract}
A b s t r a c t. This study evaluated the kinetics of water vapour adsorption on the surface of starch molecules derived from wheat. The aim of the study was to determine an equation that would allow estimation of water content in tested material in any timepoint of the adsorption process aimed at settling a balance with the environment. An adsorption isotherm of water vapour on starch granules was drawn. The parameters of the Guggenheim, Anderson, and De Boer equation were determined by characterizing the tested product and adsorption process. The equation of kinetics of water vapour adsorption on the surface of starch was determined based on the Guggenheim, Anderson, and De Boer model describing the state of equilibrium and on the model of a first-order linear inert element describing the changes in water content over time.

$\mathrm{K}$ e y w o r d s: sorption isotherms, adsorption kinetics glutenfree starch, Guggenheim, Anderson and De Boer model
\end{abstract}

\section{INTRODUCTION}

Absorption of water vapour by food products determines their stability and safety (Barnwal et al., 2012). Research into water vapour adsorption usually involves adsorption isotherms set with static methods in order to explain the relationship between water content in food and relative humidity equilibrium in the surrounding atmosphere. It provides information on the mechanism of water binding during its interaction with the food matrix, especially when thermodynamic properties are included. In addition, it is a source of useful information for evaluation of food processing technologies such as drying, mixing, and storing. It can also be used for testing structural characteristics of food products eg specific surface, size distribution of pores, and crystal-

*Corresponding author e-mail: a.ocieczek@wpit.am.gdynia.pl line structure. This data can be applied to optimize storing conditions and packaging systems that stabilize the nutritional value of food products (Pałacha and Sitkiewicz, 2010).

An adsorption isotherm is a graphic representation of the relationship between water mass per dry matter and water activity in a given constant temperature and describes the state of dynamic equilibrium of a system. Our attention should focus on the complex nature of water vapour adsorption in food products. In the case of biopolymers, absorption of water includes not only adsorption, but also structural changes of the polymer matrix due to swelling of some of its components. A sigmoid adsorption curve indicates a process of creation of multi-molecular layers of water on the surface $e g$ of starch granules (Limousin et al., 2007) and describes a triple-phasedadsorption process. In thefirstphase, polar groups of hydrophilic components, with high binding energy, are saturated with water molecules. In the second stage, other water molecules are bound to the filled monolayer and water starts to form clusters. During the third phase, water accumulates in the intercellular spaces, which results in partial swelling that consequently leads to loosening of the macromolecule structure and exposure of additional hydrophilic sites (Pałacha and Sitkiewicz, 2010).

Solid bodies have an irregular structure and defects such as fissures and dislocations, both internally and on the surface of a solid body. Even crystals show diversification of individual crystalline planes. Adsorption properties on a smooth surface are different from those on a margin or in a corner. Therefore, the surface of real adsorbents should not be regarded as homogeneous. Food products are thus heterogeneous in the chemical composition and structure,

(C) 2015 Institute of Agrophysics, Polish Academy of Sciences 
which influence the capacity for water vapour absorption from the environment. The analysis of adsorption kinetics should include the fact that the rate of adsorption may be determined by the degree of filling of the adsorbent surface with adsorbate molecules, which is conditioned by intermolecular interactions of the adsorbate (Lewicki et al., 1977).

Starch is composed of two polymers: linear ie amylose, and branched ie amylopectin. All types of starch contain both polymers. In a native state, starch has an organized structure composed of granules and is similar to crystals. Both polymers have a laminar and radial arrangement with aldehyde groups projected externally. Starch of cereal origin ( $\mathrm{eg}$ wheat starch) has a crystal form with a concentric arrangement. Starch granules are macromolecules rich in polar sites (-OH, $-\mathrm{SH}$ groups), which enable significant adsorption of humidity (Ocieczek, 2007). The adsorption capacity of starch largely depends on the arrangement of polar groups, the availability of these groups for water, the degree of matrix crystallization, the relative strength of water-water and water-macromolecule interactions, as well as the conditions of relative humidity (Pałacha and Sitkiewicz, 2010). Some of these characteristics are reflected in the parameters of the Guggenheim, Anderson and De Boer (GAB) equation and features that can be calculated based on the parameters of the GAB equation. The parameters of the GAB model are determined based on the empirical data describing the isotherms in a 0.07-0.98 $a_{w}$ range. The GAB model is recommended by the European Project Group COST 90 to describe the water adsorption process by food products (Blahovec and Yanniotis, 2008; Timmermann, 2003).

The capacity of the monolayer $\left(v_{m}\right)$ defines the adsorption capacity of adsorbents, serves as an index of availability of polar sites for water vapour, and determines the volume of water that is strongly bound to the food matrix (Pałacha and Sitkiewicz, 2010). The deviations of the parameters of the GAB equation, based on the BET theory, from the parameters of the BET equation are described by the value of the $K$ parameter in the GAB equation. The value of the $\mathrm{K}$ parameter allows us to determine whether the GAB equation may be applied to describe a set of empirical data. Lewicki (1997) proved that the GAB equation might be used to describe an experiment only when $0.24<K \leq 1$. The $K$ parameter serves as a constant that corrects the features of molecules localized in the adsorptive multi-layer in relation to the liquid phase. The magnitude of the $K$ parameter not only indicates the range of application of the GAB equation, but also describes monomolecular $(K \leq 0.5)$ and multi-layer $(K>0.5)$ adsorption (Caurie, 2006). Chirife and Iglesias (1992) reported that the value of the $K$ parameter depended on the type of the described product. However, it is impossible to explain whether this relation results from a mathematical form of the model or has any physical meaning. The $\mathrm{C}$ constant is the second parameter that indicates that the GAB model is useful to describe specific sets of data. According to Lewicki (1997), this parameter should fall in the range from 5.67 to infinity. The energy constant
$\mathrm{C}$ reflects the difference between desorption enthalpy from a monolayer and enthalpy of liquid evaporation of an adsorbent. The value of enthalpy of physical adsorption is approx. $20 \mathrm{~kJ} \mathrm{~mol}^{-1}$ and does not influence the state of physically adsorbed molecules (Atkins, 2003). There are some reports which indicate that the energy constant $C$ may lack a physical sense due to mathematical compensation of parameters found in each procedure of curve matching (Blahovec, 2004; Pérez-Alonso et al., 2006).

Assuming heterogeneity and porosity of biological materials, the state of saturation of a solid body surface with water vapour during the adsorption process depends on its duration. The aim of the paper was to create a kinetic model for determination of the state of saturation of gluten-free wheat starch with water vapour at any time-point during the adsorption process $\left(v_{t}\right)$ leading to a state of humidity equilibrium (v) estimated with the GAB model.

\section{MATERIALS AND METHODS}

The studies were carried out on gluten-free wheat starch commercially manufactured by Label Articles Gluten-Free 'BEZGLUTEN' S.c., Koniusza, Poland. The experimental material was stored in accordance with the manufacturer recommendations specified on the packaging.

Water content in the tested material was determined with a drying method (at $105^{\circ} \mathrm{C}$ ) according to the procedure described in AACC (2000) in grams per $100 \mathrm{~g}$ d.m.

The water activity was evaluated in AquaLab (Series 3, TE model, Decagon Devices, Inc., Pullman, WA, USA) with an accuracy of \pm 0.003 at $293.15 \mathrm{~K}\left(20^{\circ} \mathrm{C}\right)$.

The adsorption isotherms were determined with the static-desiccator method, according to the procedure described by Ocieczek (2012).

GAB equation parameters of the formula (Blahovec and Yanniotis, 2008):

$$
v=\frac{v_{m} C K a_{w}}{\left(1-K a_{w}\right)\left(1-K a_{w}+C K a_{w}\right)}
$$

where: $a_{w}$ - water activity, $v$ - equilibrium water content ( $\mathrm{g} \mathrm{H}_{2} \mathrm{O} 100 \mathrm{~g}^{-1}$ d.m.), $v_{m}$ - water content in the monolayer ( $\mathrm{g} \mathrm{H}_{2} \mathrm{O} 100 \mathrm{~g}^{-1} \mathrm{~d} . \mathrm{m}$.), $C$ - energy constant of Guggenheim, $K$ - constant correcting properties of multilayer molecules in relation to the liquid phase.

GAB equation parameters were determined based on the empirical data, in accordance with the procedure described by (Ocieczek and Kostek, 2009). The calculations were performed using MS Excel 2003. The errors of the determined equation parameters were detected with the SolverAid macro command.

The kinetics of water vapour adsorption was determined with a dynamic method using a measurement station, which allowed constant measuring of sample mass. The implementation of POMIAR WIN software enabled us to record the changes in the mass of the tested samples. 
The kinetics of water vapour adsorption was determined based on the changes in the water content of the samples. The experiment was carried out on app. $2 \mathrm{~g}$ starch samples with initial humidity $\left(v_{w}\right)$ of $12.5 \%$ and water activity that equalled 0.415 , the samples were collected directly from a hermetically closed container. The starch samples were placed in environments with water activity $0.0698,0.2310$, 0.4400 , and 0.6986 regulated respectively with the following solutions of salts: $\mathrm{NaOH}, \mathrm{CH}_{2} \mathrm{COOK}, \mathrm{K}_{2} \mathrm{CO}_{3}$, and $\mathrm{KJ}$.

The measurements were taken in a climatic chamber at $20^{\circ} \mathrm{C} \pm 1^{\circ} \mathrm{C}$ for $48 \mathrm{~h}$.

It was assumed that the kinetics of water vapour could be described with the following first-order linear difference equation:

$$
\frac{d v_{t}}{d t}=\frac{\left(v-v_{t}\right)}{\mathrm{T}}
$$

where: $t$ - time, $\mathrm{T}$ - time constant, $v$ - equilibrium water content described with the GAB model, $v_{t}$ - water content in starch at a given time-point $t$.

\section{RESULTS AND DISCUSSION}

In the tested material, the initial water content $\left(v_{w}\right)$ was $12.5 \%$ and the water activity was 0.415 . The determined isotherm (Fig. 1) reflected the physical adsorption process on a porous body and therefore yielded a curve typical of type II isotherms.

The adsorption of water vapour increased in the whole aw range. The determined adsorption isotherm was continuous across the whole range of water activity. This means that during adsorption of water, no change in the structure conditioned by an increase in the arrangement of starch granules occurred; this phenomenon may be observed in

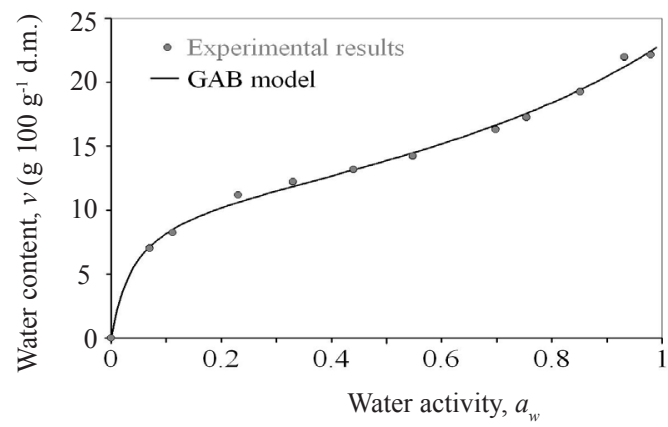

Fig. 1. Isotherm of water vapour adsorption on gluten-free wheat starch. some dried dairy products (Pałacha and Sitkiewicz, 2010). The adsorption of water was particularly evident above $0.75 a_{w}$, which might be attributed to the effect of capillary condensation.

The parameters of the GAB equation $\left(v_{m}, C, K\right)$ and the value of water activity corresponding to monolayer covering and the errors in the determined parameters are presented in Table 1.

The determined capacity of the monolayer (Table 1) corresponded to the values reported by Karel (1975) for different food products. The activity of water corresponding to the monolayer indicated that the tested product was microbiologically safe. The GAB model was suitable for describing the isotherms of water vapour adsorption on the surface of gluten-free wheat starch. In addition, the parameters of the $\mathrm{GAB}$ equation indicate that the tested process is a multilayer physical adsorption.

Water vapour adsorption on food products proceeds with varied speed depending on the nature of the food product and the relative humidity of the environment. Starch is a relatively homogenous material with a significant rate of adsorption, which is determined by a high number of adsorption centres with a balanced energy level (Lewicki et al., 1977). Studies on the kinetics of water vapour adsorption by selected food products carried out by Lewicki et al. (1977) revealed that the impact of relative air humidity on the mechanism of adsorption depended on the nature of the product. Starch does not show any change in the adsorption mechanism under the influence of relative air humidity and its speed depends on the volume of adsorbed water. Changes in the adsorption mechanism affect amorphous products and are most often determined by structural conversions of components such as swelling, increased mobility of protein chains, or presentation of new adsorption centres. The rate of adsorption increases significantly as a result of these transformations and this process per se involves more centres available for water molecules. Following absorption of a given volume of water, amorphous components evolve into a crystalline form, which absorbs a small amount of water in the medium range of relative humidity of air. The mechanism of adsorption changes after crystallization. At a low degree of adsorption, its speed depends on the volume of adsorbed water. In the next stage, adsorption speed depends to a minor extent on the degree of adsorption. In the final phase, adsorption speed is again significantly determined by its degree. The change in adsorption speed depending on its degree

T a b l e 1. Parameters of the GAB equation and water activity values corresponding to monolayer covering determined for gluten-free wheat starch

\begin{tabular}{lcccc}
\hline Results of point estimation & $v_{m}=10.54$ & $K=0.5556$ & $C=46.85$ & $a_{w}=0.2294$ \\
\hline $\begin{array}{l}\text { Estimation of SD for tested } \\
\text { parameters }\end{array}$ & $\sigma_{v m}=0.32$ & $\sigma_{K}=0.0163$ & $\sigma_{C}=7.45$ & \\
\hline
\end{tabular}


is consistent with the theory of multilayer adsorption and capillary condensation (Galus et al., 2012). In the case of small covering of adsorbent surface with water molecules (adsorbate), intermolecular interactions have a significant impact on the energy status of an adsorbent surface and the adsorption then proceeds quickly. After filling all available active centres (though of different values), intermolecular interactions become homogeneous, mainly of a water-water type. The speed of adsorption becomes less dependent on the volume of adsorbed water. This progressive process of adsorption results in filling some of the capillaries, which is called 'capillary condensation'. In this stage of the adsorption process, the curvature of the meniscus is determined by the amount of adsorbed water and the speed of adsorption again becomes dependant on its degree. Lewicki et al. (1977) concluded that the correlation between the speed of adsorption and its degree might serve as a basis for measuring the capacity of the monolayer and the content of water that initiated capillary condensation.

The GAB model used in this experiment to describe parametrically the state of equilibrium requires carrying out an experiment for a relatively long period. Therefore, the changes in starch humidity are presented below over a time function and they characterize the kinetics of adsorption. The unknown state that was not in equilibrium was thus described.

Inert models are implemented in mechanics, biomechanics, electrical engineering, heat engineering, and in many other scientific disciplines. A first-order linear inert element is used to model configurations that have a certain degree of inertia and require time to set a given state of equilibrium. The increase in the tested value in a linear model is proportional to the difference between the value corresponding to the state of equilibrium in certain conditions and the current value (Eq. (3)). In other words, the increase in product humidity over time is proportional to the difference between humidity in an equilibrium state and humidity in a given time-point. The intuitive explanation may be that, initially, a water molecule easily finds an optimal site for adsorption, whereas over time, the best sites are occupied and a smaller surface is left for filling. Therefore, the process of adsorption slows down over time. For a high activity of water and dry product, adsorption of molecules runs initially on a dry surface and then on subsequent layers of water molecules, which additionally slows down this process.

The experiment per se consists in identifying the time constant $\mathrm{T}$ of the Eq. (3). This constant was identified based on the changes in product humidity recorded over time. A product with known humidity was placed in an atmosphere with known water activity $\left(a_{w}\right)$ which corresponded to a step function. The response of inert configuration to the step function is described with Eq. (4). Assuming minimizations of quadratic residues as an objective function and the application of a non-linear regression, the time constant
$T$ was identified. The experiment, planned and organized in this manner, enables identification of the parameters of Eq. (3).

The following exponential function is the solution of Eq. (3) for water activity constant:

$$
v_{t}=v_{w}+\left(v-v_{w}\right)\left(1-e^{\frac{-t}{\mathrm{~T}}}\right)
$$

where: $v_{t}$ - water content in starch in $t$ time, $v_{w}$ - initial humidity of starch for $\mathrm{t}=0, v$ - water content in starch in the humidity equilibrium state estimated based on the GAB model, $\mathrm{T}$ - time constant, $t$ - time.

The above equation describes a first-order linear inert element that is commonly used in automatic control engineering for modelling numerous phenomena. A similar approach to modelling the kinetics of adsorption has been presented by Noorbakhsh et al. (2006) and Švábová et al. (2011).

The $v_{w}$ parameter describes the content of water in the tested material in $\mathrm{t}=0$ time of adsorption kinetics and, thus, the initial content of water in starch, and is regarded as a known value. The identification was therefore limited to the $\mathrm{T}$ parameter; the direct method was applied and $\mathrm{T}$ was determined based on the recorded time courses. The method of identification is discussed above. The identified time constant is $\mathrm{T}=22830 \mathrm{~s}$. The results of identification are presented in Fig. 2.

The results indicate sufficient compatibility between the experimental results and the results of theoretical calculations, which proves good reflection of the described phenomenon. The mathematical model of the kinetics of adsorption obtained may be regarded as valuable. Some differences between theoretical and experimental results may be a consequence of the heterogeneity of the material in terms of its humidity and adsorption characteristics. The weight of samples, distribution of material on a plate, and time between consecutive measurements could also exert an impact. The samples may have absorbed moisture or become dried. Therefore, further work into this subject will be conducted. Further studies will consist of experimental verification of the model in different water activities and initial humidity of material. The studies will include both adsorption and desorption.

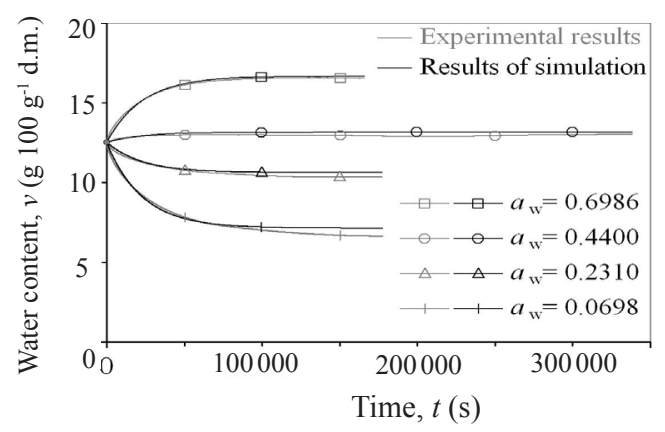

Fig. 2. Comparison of the experimental results of kinetics with the calculations for the determined model of adsorption kinetics. 


\section{CONCLUSIONS}

1. The presented equation sufficiently describes the kinetics of adsorption and desorption of water on a starch surface for the examined activities of water and humidity of starch. This equation is based on the Guggenheim, Anderson and De Boer model and the model of the firstorder linear inert element. The Guggenheim, Anderson and De Boer model describes the state of equilibrium, whereas the inert element models present changes in humidity over time.

2. The time constant of the inert element is a parameter that characterizes the process of establishing equilibrium. In the presented model, it was assumed that the time constant did not depend on water activity or humidity of material and was regarded as fixed for this material. The time constant depends on the course of adsorption and desorption on the sorbent surface. Furthermore, it depends on the physical and chemical interaction between the sorbent and water molecules (eg swelling, dissolving, crystallization).

\section{REFERENCES}

AACC, 2000. Approved methods of Analysis of the American Association of Cereal Chemists. American Association of Cereal Chemists. St. Paul, MN, USA.

Atkins P.W., 2003. Physical chemistry (in Polish). Wydawnictwo Naukowe PWN, Warsaw, Poland.

Barnwal P., Kadam D.M., and Singh K.K., 2012. Influence of moisture content on physical properties of maize. Int. Agrophys., 26, 331-334.

Blahovec J., 2004. Sorption isotherms in materials of biological origin mathematical and physical approach. J. Food Eng., $65,489-495$.

Blahovec J. and Yanniotis S., 2008. GAB generalized equation for sorption phenomena. Food Bioprocess Technol., 1, 82-90.

Caurie M., 2006. The derivation of the GAB adsorption equation from the BDDT adsorption theory. Int. J. Food Technol., 41, 173-179.

Chirife J. and Iglesias H.A., 1992. Estimation of precision of isosteric heat of sorption determined from the temperature dependence of food isotherms. Lebensmittel-Wissenschaft und-Technologie, 25(1), 83-84.
Galus S., Turska A., and Lenart A., 2012. Sorption and wetting properties of pectin edible films. Czech J. Food Sci., 30(5), 446-455.

Karel M., 1975. Water activity and food preservation W: Physical principles of food preservation. Principles of food science. Part 2. (Eds M. Karel, O.R. Fennema, D.B. Lund). Marcel Dekker Press, New York, USA.

Lewicki P.P., 1997. The applicability of the GAB model to food water sorption isotherms. Int. J. Food Sci. Technol., 32, 553-557.

Lewicki P.P., Lenart A., Placzek A., and Skrzeszewski S., 1977. Kinetics of water vapor sorption by selected food products (in Polish). Przemysł Spożywczy, 41(11), 428-432.

Limousin G., Gaudet J.-P., Charlet L., Szenknect S., Barthès V., and Krimissa M., 2007. Sorption isotherms: A review on physical bases, modeling and measurement. Applied Geochem., 22, 249-275.

Noorbakhsh S., Tabil L. JR., and Ghazanfari A., 2006. Analysis and modeling of water absorption by yellow dent corn kernels before and during gelatinization process. Asian J. Plant Sci., 5(5), 805-810.

Ocieczek A., 2007. Comparison of sorption properties of semolina and farina. Acta Agrophysica, 146, 135-145.

Ocieczek A., 2012. Hydratation properties of machine wheat flours as a discriminant of the usable quality (in Polish). Wydawnictwo Akademii Morskiej, Gdynia, Poland.

Ocieczek A. and Kostek R., 2009. The effect of micronization on sorptive properties wheat cellulose. Inżynieria i Aparatura Chemiczna, 48(40), 108-109.

Palacha Z. and Sitkiewicz I. (Ed.), 2010. The physical properties of the food (in Polish). WNT, Warsaw, Poland.

Pérez-Alonso C., Beristain C.I., Lobato-Calleros C., RodríguezHuezo M.E., and Vernon-Carter E.J., 2006. Thermodynamic analysis of the sorption isotherms of pure and blended carbohydrate polymers. J. Food Eng., 77, 753-760.

Švábová M., Weishauptová Z., and Přibyl O., 2011. Water vapour adsorption on coal. Fuel 90, 1892-1899.

Timmermann E.O., 2003. Multilayer sorption parameters: BET or GAB values? Colloids and Surface A: Physicochemial Eng. Aspects, 220, 235-260. 